\title{
A Web 2.0 Supported Business Process Management Environment for Collaborative Research
}

\author{
Asli Sencer \\ Bogazici University, Management Information Systems Department, Istanbul, 34342, Turkey \\ Email: asli.sencer@boun.edu.tr \\ Meltem Ozturan \\ Bogazici University, Management Information Systems Department, Istanbul, 34342, Turkey \\ Email: meltem.ozturan@boun.edu.tr \\ Hande Kimiloglu \\ Bogazici University, Management Information Systems Department, Istanbul, 34342, Turkey \\ Email: hande.kimiloglu@boun.edu.tr
}

\begin{abstract}
Collaborative research includes research activities conducted by a group of people working at different locations and has become a hot issue due to the effects of globalization and advances in information technology (IT). The aim of this study is to design, develop, implement and evaluate an IT environment to better manage the standard processes of a collaborative research by providing more efficient use of the resources. Inspired by the studies in the literature, the basic steps and requirements of a typical collaborative research are identified and the related process flow diagram is generated. Next a Web 2.0 supported business process management (BPM) environment is developed in the direction of the process flow diagram to support collaborative researches. A commercial BPM system is used to automate and monitor the processes, whereas Web 2.0 platform is used for communications management, workspace sharing and data collection. The proposed environment is experimented by a case study conducted with a group of researchers; its performance is evaluated and directions for improvements are identified. It is concluded that in general the Web 2.0 supported BPM environment is functional, reliable and useful for collaborative research. The environment is found to be more suitable for research support processes compared to basic research processes.
\end{abstract}

Index Terms - Collaborative research, business process management (BPM), Web 2.0, information technology (IT) utilization.

\section{INTRODUCTION}

Collaboration has always been a preliminary concern for the researchers and substantial amount of studies have been made to discover its forms, properties, functionalities and implications. A clear cut definition which is agreed by all researchers still does not exist, mostly due to the effects of dynamic environmental conditions on human collaboration. Aligned with the impacts of globalization and advances in information and communication technologies there has been a considerable increase in the number, size and diversity of collaborative research projects [1]. Besides world of science, international research organizations like European Commission and policy makers extensively promote collaborative research mostly due to the benefits obtained by integration of different environments $[1,2,3$, $4,5]$.

In coherent terms, collaborative research includes research activities conducted by individuals or groups, between or within different disciplines, countries, organizations and/or locations $[1,2,6]$. Thus a collaborative research requires the management of a flow of processes that should be handled by researchers most likely in different locations. In addition to the challenges arising merely from the nature of human collaboration like difficulty in achieving consensus, ethical/legal problems due to ownership, distribution of power, risk between partners and difficulty of cultural differentiations, a collaborative research includes additional financial, timing and managerial costs $[2,6,7,8,9,10,11,12,13$, 14]. As the team size and the diversity of the locations increase, the management of the research processes becomes even more challenging and this necessitates the use of specialized information technology (IT) environments to reinforce the basic and support research processes $[15,16]$.

The studies in the literature show that although collaboration has rich outputs in research, a lot of effort has to be spent until a balanced state of cooperation is reached between different participants [17]. At this point, business process management (BPM) systems, which help organizations to efficiently manage their processes, might play a key role to overcome the difficulties of 
collaborative research. The underlying idea of developing a BPM system is to automate the steps of a research to better track and monitor its development and improve processes' productivity by providing more efficient use of the resources. Actually a collaborative research requires several other functionalities which are specific to team collaboration such as performing meetings, sharing ideas and documents, etc. At this instant, Web 2.0 platform, which allows users to interact, collaborate, and share information and workspace with each other, could help researchers. Thus, it is necessary to design an IT environment, which handles the required functionalities of a collaborative research comprehensively.

With these inspirations, a literature survey is provided in the next section to highlight the collaborative research processes and the type of IT usage proposed. In Section III, a Web 2.0 supported BPM environment is designed, developed and implemented with a case study. The findings of the study are discussed in Section IV and the contributions are presented in Section V.

\section{LITERATURE SURVEY}

Although there are various studies in literature about IT usage in collaborative research, there still seems to be dispersed opinions about in which collaborative research processes IT can be used effectively. It should be noted that research processes are primarily human rather than mechanistic in nature; that is the primary activities are concerned with the interactions of people rather than machines [18]. Although collaboration is heavily promoted in e-science and IT is found to have significant potential to facilitate cooperative research, actual collaborative research processes have been difficult to achieve in practice and IT should be evaluated carefully to determine best practices $[19,20]$. In this context, Table 1 lists the processes that are seen as grounds of collaborative research together with the agreement of IT usage in these processes according to previous studies. Table 2 lists the related IT tools for collaborative research.

Table 1. Collaborative Research Processes Where IT Can Be Used

\begin{tabular}{ll}
\hline Processes & References \\
\hline Basic Research Processes & \\
Establishment of theoretical base & Ref. [21] \\
Research design and methodology & Ref. [22] \\
Data collection & Refs. [22, 23] \\
Analyses and interpretation & Refs. [22, 24] \\
Reporting and final evaluation & Ref. [24] \\
Research Support Processes & \\
Objectives setting & Refs. [20, 24] \\
Project planning & Refs. [4, 5, 18, 22, 23, 24] \\
Communications management & Refs. [ 4, 15, 20, 22, 23, 24, 25] \\
Workspace sharing & Refs. [15, 20, 23, 24, 25, 26] \\
Monitoring & Refs. [15, 18, 24] \\
\hline
\end{tabular}

Table 2. IT Tools For Collaborative Research

\begin{tabular}{ll}
\hline IT Tools & References \\
\hline Office tools & Ref. [15] \\
Communication tools & Refs. [4, 15, 20, 21, 22, 23, 27, 28] \\
Video conferencing & Refs. [4, 20, 23, 29] \\
Web 1.0 environment & Refs. [4, 15, 21, 23, 28, 30, 31] \\
Web 2.0 platform & Refs. [15, 20, 22, 23, 24, 30, 32, 33] \\
Analysis tools & Refs. [32, 34] \\
Resource sharing environments & Refs. [19, 20, 27, 35] \\
Management tools & Refs. [18, 20, 22, 24, 27, 36] \\
\hline
\end{tabular}

In a comprehensive review, the potentials of Web 2.0 technologies and social software in execution and coordination of collaborative research activities are presented [37]. Meanwhile the pitfalls of using ICT in collaborative research such as requirement for high level of technology readiness, difficulty in adapting to new settings and the challenge of building trust have been highlighted [38]. Other challenges that are found to be important in both science \& engineering and behavioral \& social sciences domains are usability, unreliability of technology, cost, ineffectiveness of ICT mediated communication, variance in tool availability and competence among researchers [39].

In spite of comprehensive opinions about IT usage in collaborative research, there are few IT-based systems proposed for supporting the processes of collaborative research. In one of these systems, a framework has been developed for an integrated information system for collaborative research, offering special services for doctoral studies and research activities by considering all relevant aspects of education and research as being parts of processes [24]. In another system, the design principles aiming to support research collaboration have been identified using Viable Systems Model (VSM) [18]. Furthermore, a research project has been conducted where a system prototype has been developed that supports group communication and knowledge sharing via the Wiki-based platform [25].

\section{Methodology}

In this study, based on the literature survey summarized above and in the direction of the requirements determined in the research project [17] which this study is also a part of, initially a process flow diagram for a collaborative research is designed, secondly a Web 2.0 supported BPM environment is developed in the direction of the process flow diagram, and finally the environment is experimented with a case study.

\section{A. Design of the Process Flow Diagram for a Collaborative Research}

According to the literature summarized and to the findings of the research project [17], a typical collaborative research should include the following main steps; review of the related literature, development of the theoretical model, design of the survey, collection of the data, analysis of the collected data and generation of the 
project report. A collaborative research further requires periodic or occasional meetings where the ideas are shared and discussions are made to determine the future direction of the research. Thus the flow in the BPM system should include planned meetings in every step of the research and the BPM system should provide a computerized platform to perform these meetings from distant locations. Moreover, a common workspace should be created where the studies in distributed locations can be uploaded and shared with the research team members.

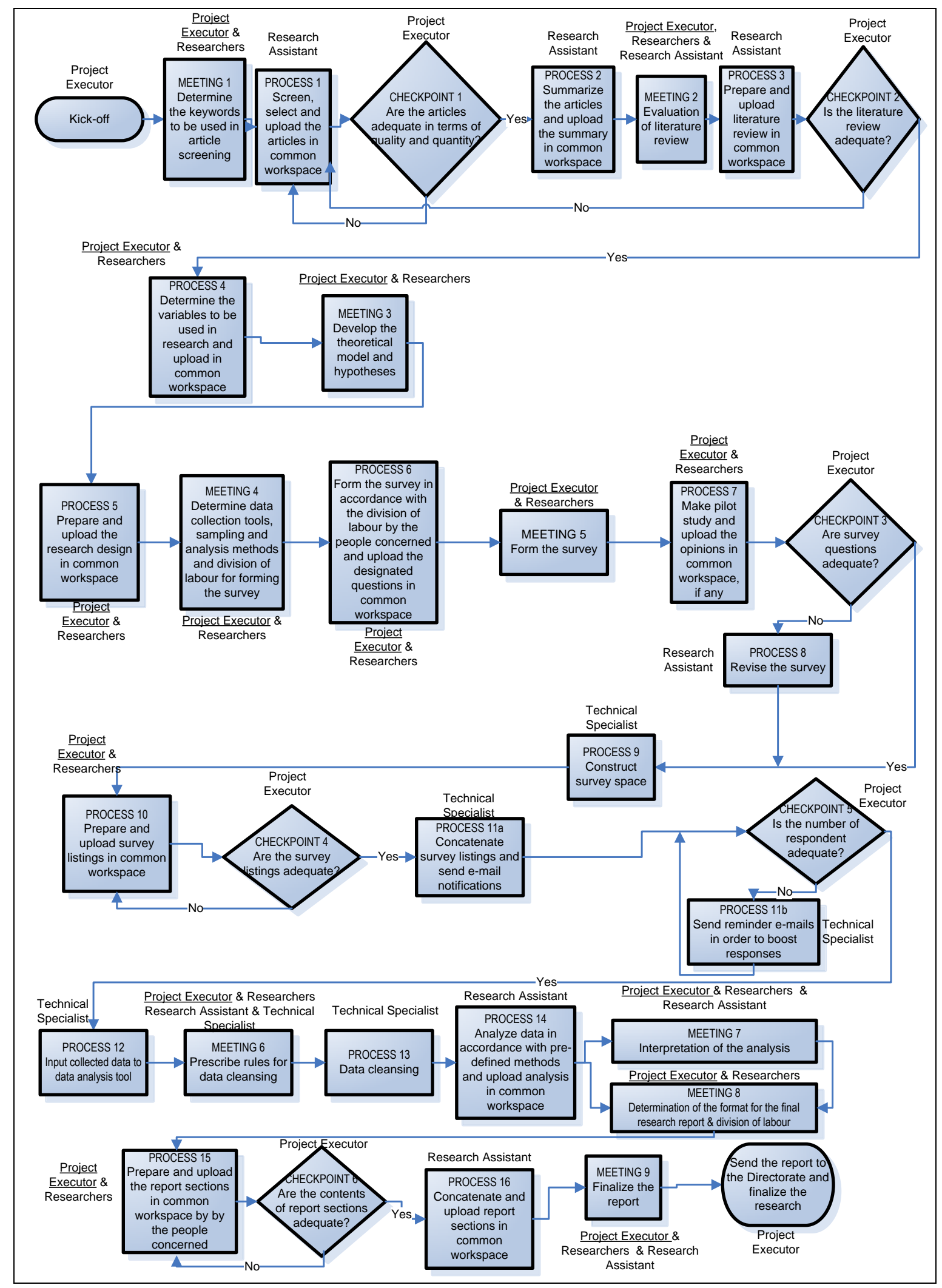

Fig. 1. Process flow diagram for collaborative research 
A collaborative research project team is usually composed of a project executor, a group of researchers, a group of research assistants and a group of technical specialists. The project executor is responsible for the general management of the project that includes task assignments to the team members, general monitoring of the quality of the research processes and performance evaluation of the researchers. The researchers take part in the scientific development of the research by the support of the research assistants. Technical specialists provide technical support to the researchers for the information systems used.

Based on the above requirements of a collaborative research, the flow diagram of the standard processes of a collaborative research study is prepared as given in Fig. 1. The flow includes the individual activities and the meetings to be performed during the study. The owners of these activities and the correspondents of the meetings are also shown. In the direction of the flow, the project starts with the kick-off of the project executor, continues with the execution of the research processes defined and is finalized with the submission of the research report.

B. Development of a Web 2.0 Supported BPM Environment for Collaborative Research

In the next step of the study, a BPM system that has been developed by a Turkish company for business use is chosen as the BPM system to model, implement and experiment the process flow of the collaborative research. The modeling module of the BPM system is used to generate the business process model that includes the same processes as in Fig. 1 with the additional reminder processes where email messages are sent to the selected members by the project executor to invite them to a meeting or to assign a process to a specific member.

According to the flow of the processes modeled in BPM system, it is required to start the project by the project executor's message and then to e-mail reminders automatically to the relevant members of the team for the succeeding processes. Each person who takes part in the research has to check his or her inbox in order to monitor the track of the processes and should undertake each piece of work upon which the project executor has previously entailed.

The process flow of a collaborative research in Fig. 1 includes several meetings that should be handled online. Unfortunately, the chosen BPM system does not support functionalities like online conferencing or chatting. Thus it is provided that the meetings should be held on the Web 2.0 platform without coming together physically.

Furthermore, a "Collaborative Research Group" is created in the Web 2.0 platform to share a common workspace. Literature, Research Design, Report, Analyses and Meeting Minutes folders have been created in this common workspace where documents can be uploaded or downloaded by the relevant members whom the project executor assigns responsibility.

The project executor has the right to start and lead discussions and provide insight to each person involved in the research.

Web 2.0 platform is also used for designing and conducting the surveys, and collecting the data. The respondents are asked to fill and submit the questionnaire online by using this platform.

To send the survey link to all recipients, the survey management software that has been developed internally in the Center for Information Systems Research and Application (BSUYGAR) is used.

In addition to these, SPSS is proposed for data analysis and MS-Office programs are proposed for documentation and graphical work.

\section{Experimentation of the Web 2.0 supported BPM Environment with a Case Study}

In this step a case study is made to test the performance of the Web 2.0 supported BPM environment for collaborative research. For this purpose, a research topic is selected as "Identifying the Factors Affecting the Performance and Success of Exchange Students in Management Information Systems Department of Bogazici University". This collaborative research study is conducted by a team of nine members composed of a project executor, six researchers, a research assistant and a technical specialist. Prior to the case study, the team members are informed about the process flow of the collaborative research, team formation and tools to be used during the case study.

The research has been started with the kick-off of the project executor and followed by the team members in the BPM and Web 2.0 based IT environment in accordance to the processes defined in Fig. 1.

For reference, some highlights have been provided for the case study in this paper:

Fig. 2 gives the screen showing the reminder messages for the assigned tasks and meetings in the BPM system. In this screen, the description, type and status of the process; and the assignment and completion times are provided.

Fig. 3 shows the common workspace created to upload the files of studies or papers in Web 2.0 platform. It also shows the name of the researcher and the time of uploading.

A screenshot of the BSUYGAR Survey Manager is shown in Fig. 4. An example e-mail screen for a survey sent to a list of students is presented.

Fig. 5 shows an invitation for a meeting in the BPM system. Precisely the provided screen shows the invitation for Meeting 1 from the project executor including the topic of the meeting, its time and other related details. 


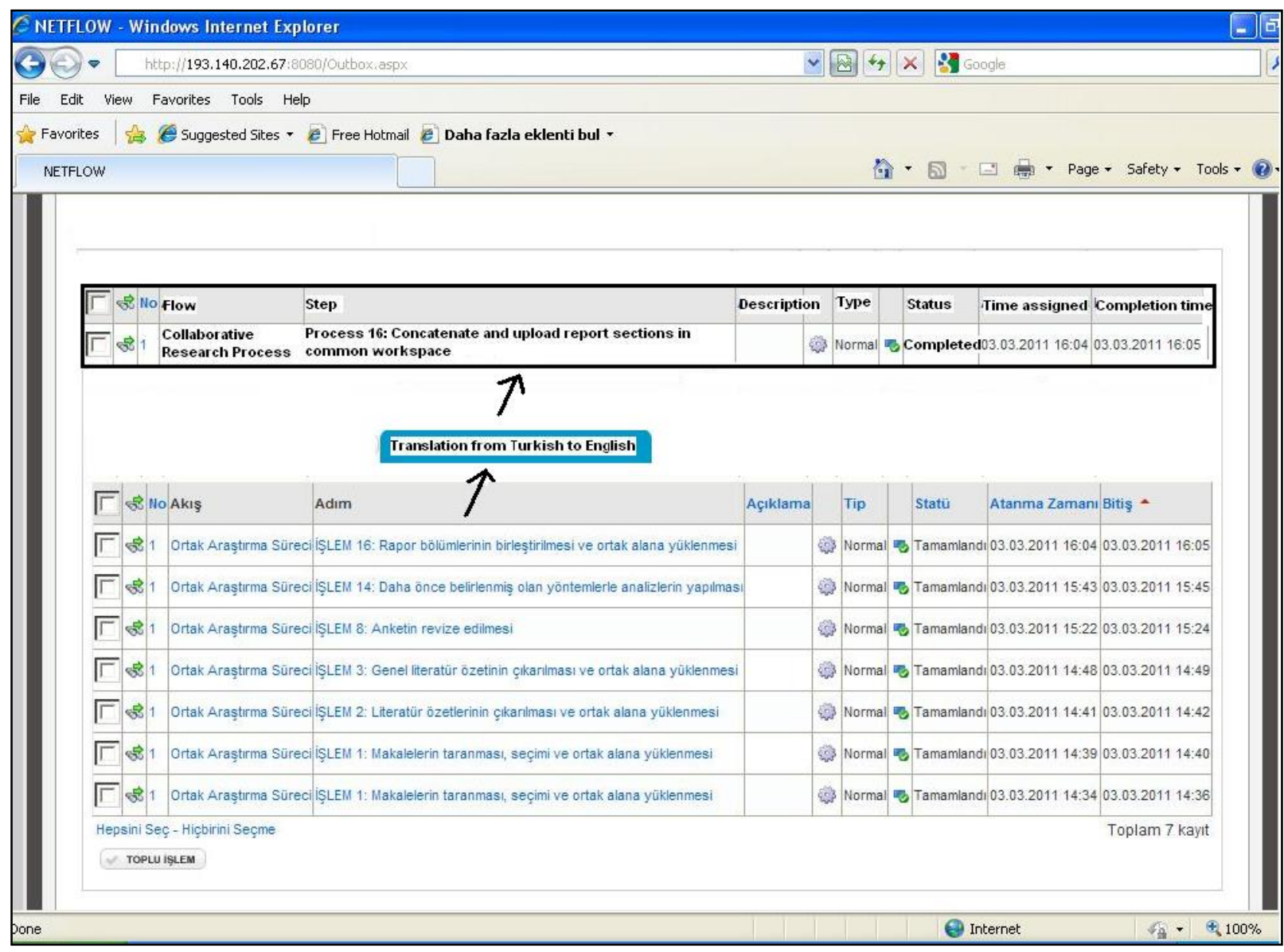

Fig. 2. BPM system screen showing the reminder messages for the assigned tasks and meetings

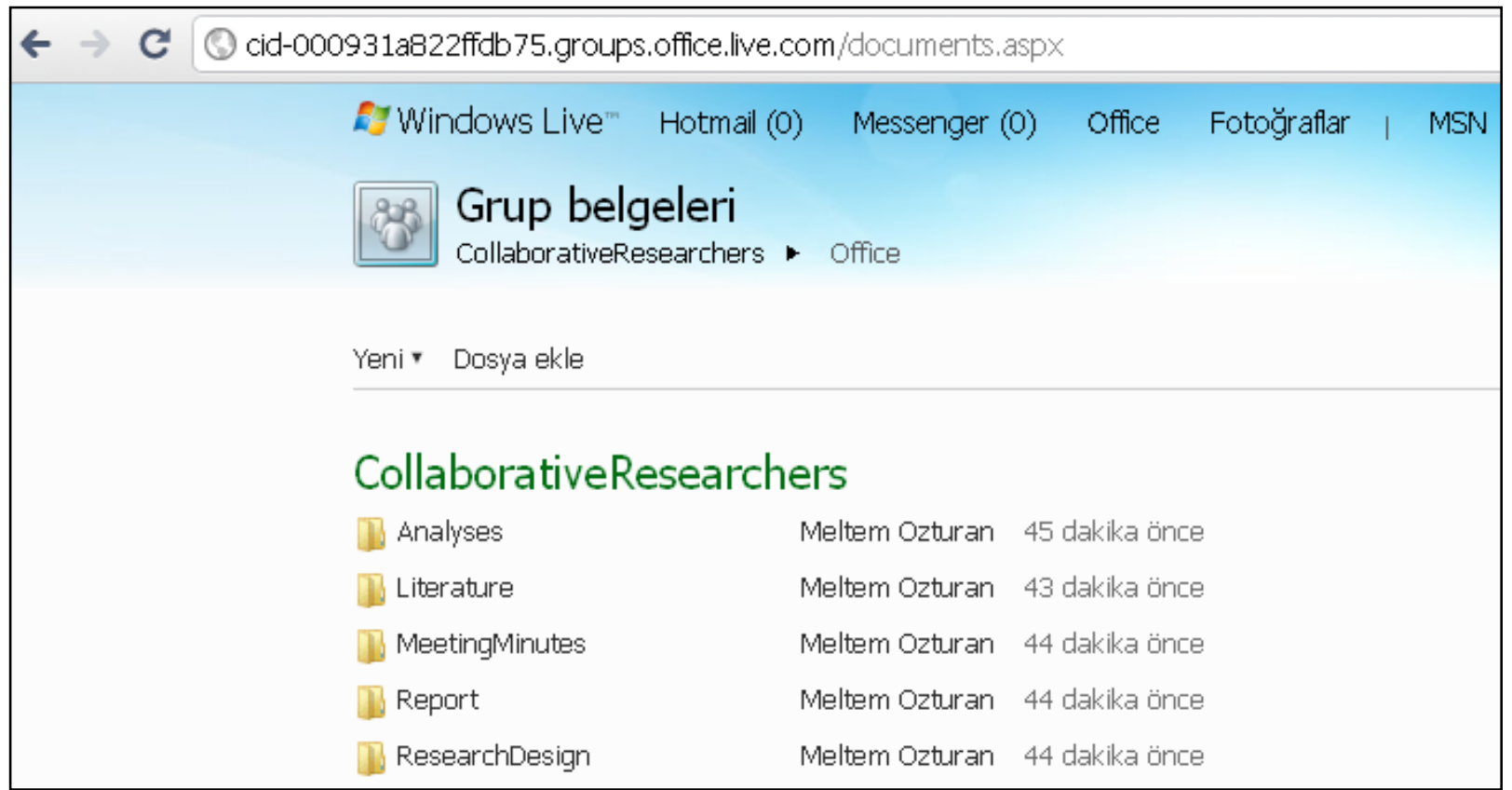

Fig. 3. The common workspace in MSN used to upload studies from distributed locations 


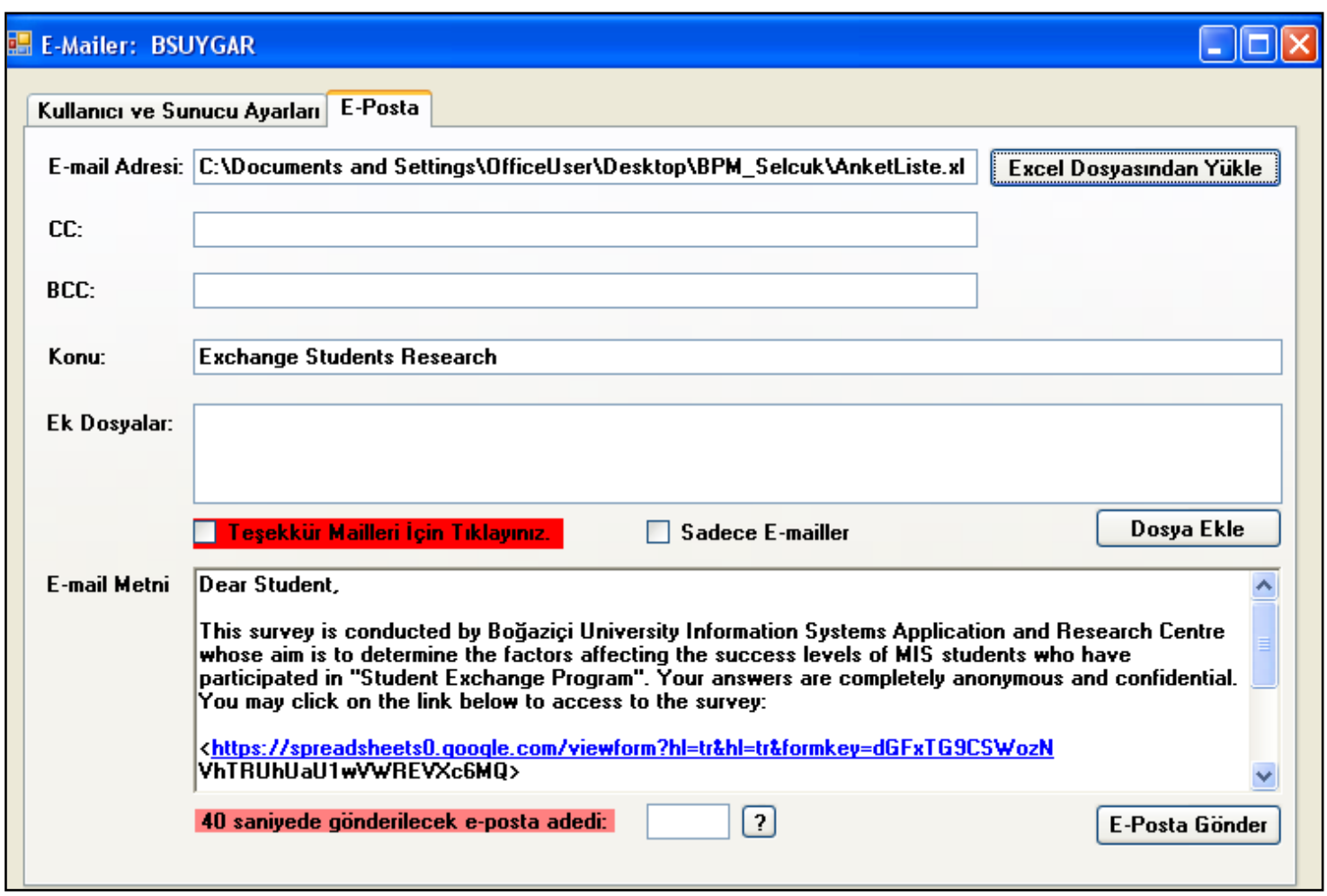

Fig. 4. Process 11b: E-mail screen of the BSUYGAR Survey Manager

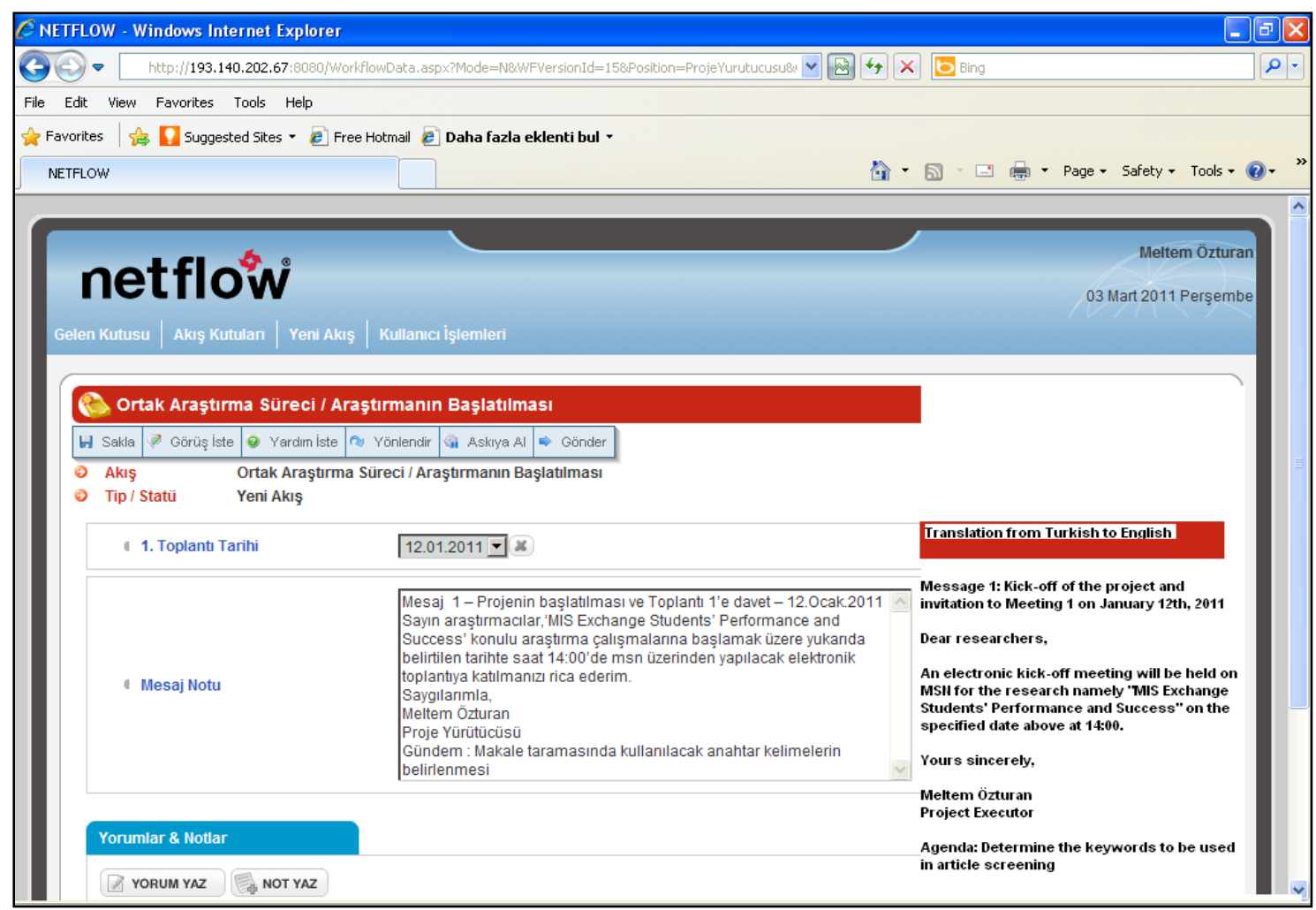

Fig. 5. Invitation for Meeting 1 from the project executor

\section{Findings OF THE STUDY}

The developed Web 2.0 supported BPM environment for collaborative research is evaluated by the members of the collaborative research team at the end of the case study. A questionnaire is designed with both closed and open ended questions to assess the environment with different dimensions. Answers are collected by using a 5point Likert scale (1-Strongly disagree; 2-Disagree; 3Neutral; 4-Agree; 5-Strongly Agree). 
At first place, the appropriateness of the environment is measured respectively for basic research processes and research support processes. Next the environment is evaluated by using the characteristics that appear in ISO/IEC 9126 Software Evaluation Standards [40]. Finally the selected BPM system and Web 2.0 platform are evaluated separately and results are compared with the general evaluation of the environment developed.

In the first part of the survey, the developed environment is evaluated in terms of the basic research processes as classified in Table 1, namely establishment of theoretical base, research design and methodology, data collection, analyses, interpretation and reporting and final evaluation. It is generally agreed that the environment is suitable for all of these processes. Among these the environment is found to be the most suitable for data collection in a collaborative research. This result is very intuitive since the environment facilitates the data collection by eliminating the need for manually inputting data into the analysis tool. In an online survey, the respondents' collected data are automatically saved and easily transferred to the analysis tool.

In the second part, the developed environment is assessed by considering the research support processes that are classified as in Table 1, i.e., objectives setting, project planning, communications management, workspace sharing and monitoring. In general it is strongly approved that the environment is suitable for all these support processes except objectives setting. Some respondents argue that objectives setting should be made by classical face to face meetings in a collaborative research. In a different argument it is stated that online meetings provide better time utilization by not allowing unnecessary chatting or repetitions; thus yield shorter meeting durations. Yet all respondents agree or strongly agree on the suitability of the environment for communications management. There are some other comments about the workspace sharing facility of the proposed environment. All respondents find very suitable to use a common workspace in a collaborative research where the team members can upload documents for sharing with the other members. It is emphasized that the use of such common workspaces is inevitable especially in collaborative research conducted by large sized groups. Among all these research support processes, the environment is found to be the most suitable for project planning due to the achievements obtained by decreased time and effort in scheduling and resource allocation.

In the third part, the developed environment is assessed with respect to the software evaluation characteristics of ISO/IEC 9126 Standards developed for an external evaluator. The evaluation is based on its six main criteria for functionality, reliability, usability, efficiency, maintainability and portability. The respondents mostly agree and strongly agree that the environment is functional, reliable and usable. The respondents are moderate about the efficiency of the environment for collaborative research. Here, efficiency is measured by the achievements obtained in time utilization, resource allocation and compliance. The reason why some respondents are neutral about the efficiency of the environment is mostly due the fact that the environment itself requires a learning process and getting used to. Thus reduction in time and effort in some processes might not be apparent at first, whereas it is supposed to improve gradually as researchers get more experienced in this environment. Maintainability and portability are the measures for which the environment is found to be the weakest. Although the selected BPM system has a test mode where any generated flow can be simulated and tested, it does not allow making changes easily in the process flow during its implementation. After all, these processes should be handled by a technical expert for the selected system. This brings a major drawback to the maintainability of the environment. Although portability is more of a technical issue, the respondents are able to make a brief assessment by drawing on the difficulties they have had in dealing with different IT system and platforms for process management, workspace sharing and communications management. Unfortunately in this study, the selected system and platform for these purposes cannot be integrated and this leads to lower evaluations of portability.

Selected system and platform specific issues are elaborated in the fourth part for general evaluation of the developed environment. All respondents agree and strongly agree that the environment in general is appropriate for collaborative research. This result assures that the respondents are satisfied by the use of such an environment in collaborative research. Yet there are some concerns about the selected BPM system and Web 2.0 platform. Almost all respondents heavily emphasize that the BPM system should provide a teleconferencing environment for meetings and a common workspace for sharing documents as well. In the current setting Web 2.0 platform is used for these purposes and this leads to lower maintainability and portability of the environment as explained above. However it should be noted that a classical BPM system is not supposed to provide functionalities for workspace sharing and advanced communications. Thus a major finding of this study is that an environment for collaborative research should provide integrated functionalities for process management, communications management and knowledge sharing.

In the open ended question of the evaluations, opinions about the selected BPM system and Web 2.0 platform are highlighted. It is indicated that the definitions of the menu items should be clearer in the BPM system. Moreover, the subjects of the task reminder emails should be clearly defined during the modeling phase to facilitate easy tracking of the tasks when the messages are listed. Additionally, the BPM system allows tracking the completed, ongoing and delayed processes in the collaborative research flow but it is difficult to follow the progress in the generated views when the flow diagram includes larger number of completed processes. In the case study, online meetings are carried out in a chatting environment. Performing meetings in chatting environment is found to be confusing and disorienting 
since the order of questions and answers are mixed, hence video conferencing is obviously a much better choice. On the other hand, the common workplace on Web 2.0 is found very adequate to share the studies conducted by different members of the research team. Finally the respondents conclude that, the Web 2.0 supported BPM environment provides better communication between the team members and it is adequate for collaborative research if it is improved in the stated directions.

\section{CONCLUSION}

Collaborative research has become a hot issue due to the effects of globalization and advances in information and communication technology. As the size, number and diversity of the collaborative researches increase, IT becomes an integral component of the research environment to manage the research processes, support communications and share information. In this study, a Web 2.0 supported BPM environment is designed, developed and implemented to better manage the standard processes of a collaborative research by providing more efficient use of the resources.

A process flow diagram is generated for the typical processes in a collaborative research, based on the IT requirements of collaborative research as indicated in the literature. The proposed process flow is modeled in the selected BPM system. The BPM system is used to trace and monitor the progress of the collaborative research study conducted by a research team. Furthermore, Web 2.0 platform is used to perform online meetings, share documents and publish online surveys. For implementation, the proposed Web 2.0 supported BPM environment is experimented by a case study conducted by a research team with nine members.

The developed environment for collaborative research is evaluated by the research team members and the findings are discussed. It is concluded that in general the Web 2.0 supported BPM environment is functional, reliable and useful for collaborative research. The efficiency obtained by using the environment is expected to improve gradually as researchers get more experienced in this environment, since the reduction in time and effort is partially a matter of getting used to. The environment is found to be more suitable for research support processes compared to basic research processes. Among all these research support processes, the environment is found to be the most suitable for project planning due to the achievements obtained by decreased time and effort in scheduling and resource allocation. Finally the respondents conclude that the Web 2.0 supported BPM environment provides better communication between the team members and it will be more adequate for collaborative research if it is improved in the stated directions.

As a future research the developed environment should be enhanced to provide the integrated management of the basic research processes, communications and workspace sharing in a collaborative research. Studies should be made to improve the maintainability and portability of the environment.

\section{ACKNOWLEDGMENT}

This study is realized at the Information Systems Research and Application Center of Bogazici University and is supported by Research Fund (Project \#: 09S112) of Bogazici University, Istanbul, Turkey. Authors like to thank Bizitek A.S., an Ericsson Company, Istanbul, Turkey for their support.

\section{REFERENCES}

[1] K. Katsouyanni, "Collaborative research: accomplishments and potential," Environ. Health-Glob., vol. 7, 2008, pp. 1-7, doi:10.1186/1476-069X-7-3.

[2] J. S. Katz and B. R. Martin, "What is research collaboration?," Res. Policy, vol. 26, 1997, pp. 1-18, doi:10.1016/S0048-7333(96)00917-1.

[3] CEC (Commission of the European Communities), "Communication from the Commission: science and technology, the key to Europe's future - guidelines for future European Union policy to support research," 2004, http://eur-lex.europa.eu/LexUriServ/LexUriServ.do?uri= COM:2004:0353:FIN:EN:PDF.

[4] J. N. Cummings and S. Kiesler, "Collaboration research across disciplinary and organizational boundaries," Soc. Stud. Sci., vol. 35, 2005, pp. 703-722, doi:10.1177/0306312705055535.

[5] G. Bammer, "Enhancing research collaborations: three key management challenges," Res. Policy, vol. 37, 2008, pp. 875-887, doi:10.1016/j.respol.2008.03.004.

[6] W.S. Barnett and E.C. Frede, "And so we plough along: the nature and nurture of partnerships for inquiry," Early Child. Res. Q., vol. 16, 2001, pp. 3-17, doi:10.1016/S0885-2006(01)00082-5.

[7] P. M. Newton and D. J. Levinson, "The work group within the organization: A sociopsychological approach," Psychiatr., vol. 36, 1973, pp. 115-142.

[8] M. LeCompte, "Some notes on power, agenda, and voice: a researcher's personal evolution toward critical collaborative research," in Critical Theory and Educational Research, eds. P. McLaren and J. Giarelli, State University of New York Press, Albany, NY, 1995, pp. 91-112.

[9] S. L. Jones, S. L. Myers, D. L. Biordi and J. B. Shepherd, "Advantages and disadvantages of collaborative research: A university and behavioral health care provider's experience," Arch. Psychiat. Nurs., vol. 12, 1998, pp. 241-246, doi:10.1016/S0883-9417(98)80033-2.

[10] A. Zervignon-Hakes, "Culture clash: translating research findings into public policy," in Early Care and Education for Children in Poverty: Promises, Programs, and LongTerm Results, eds. W. S. Barnett and S. S. Boocock, State University of New York Press, Albany, NY, 1998, pp. 245-271.

[11] K. Howe and M. Moses, "Ethics in educational research," in Rev. Res. Educ. 24, eds. A. Iran-Nejad and D. Pearson, American Educational Research Association, Washington DC., 1999, pp. 21-59.

[12] D. Caruso and D. Rhoten, "Lead, follow, get out of the way: side-stepping the barriers to effective practice of interdisciplinary - A new mechanism for knowledge production and re-integration in the age of information," 2001, http://www.hybridvigor.net/interdis/pubs/hv_pub_ interdis-2001.04.30.pdf. 
[13] J. Hermans and A. Castiaux, "Knowledge creation through university-industry collaborative research projects," 2008, http://www.mendeley.com/research/knowledge-creationthrough-universityindustry-collaborative-researchprojects- $1 /$.

[14] T. Ohta, K. J. Lee and K. Kazuhiko, "Role of formal boundary spanning structure and changing pattern of university-industry collaborative research in University of Tokyo," 2008, http://ieeexplore.ieee.org/xpls/abs_all.jsp? tp $=\&$ arnumber $=4599628$.

[15] P. Gambadauro and A. Magos, "Office 2.0: a Web 2.0 Tool for International Collaborative Research," Lancet, vol. 371, 2008, pp. 1837-1838.

[16] B. Ludäscher, I. Altintas, C. Berkley, D. Higgins, E. Jaeger-Frank, M. Jones, E. Lee, J. Tao and Y. Zhao, "Scientific workflow management and the Kepler system," Concurr. Comp.-Pract. E. Special Issue on Workflow in Grid Systems, vol. 18, 2005, pp. 1039-1065, doi:10.1002/cpe.994.

[17] M. Ozturan, A. S. Erdem and H. Kimiloglu, Business Process Management System for Collaborative Research, Bogazici University Academic Research Project Report, 2011, (Project \#: 09S112).

[18] S. Wilson, Y. Takayama, E. Ghiglione and J. Dalziel, "Designing systems for managing dynamic collaborative research processes," 2007, http://zope.cetis.ac.uk /members/scott/resources/escience_workflow.pdf.

[19] P. A. David, "Towards a cyberinfrastructure for enhanced scientific collaboration: providing its 'soft' foundations may be the hardest part," 2004, http://www.oii.ox.ac.uk.

[20] T. K. L. Schleyer, "Collaboratories: leveraging information technology for cooperative research," in $J$. Dent. Res., vol. 80, 2001, pp. 1508-1512, doi: $10.1177 / 00220345010800060601$.

[21] D. Beaver, "Reflections on scientific collaboration (and its study): past, present and future," Scientometrics, vol. 52, 2001, pp. 365-377, doi:10.1023/A:1014254214337.

[22] E. Vasileiadou, "Working apart together — Using ICTs in research collaboration," 2009, http://dare.uva.nl/document/131414.

[23] P. J. Jordan, M. G. Ory and T. G. Sher, "Yours, mine, and ours: the importance of scientific collaboration in advancing the field of behavior change research," Ann. Behav. Med. Special Supplement, vol. 29, 2005, pp. 7-10, doi:10.1207/s15324796abm2902s_3.

[24] S. Klink, A. Oberweis, D. Ried and R. Trunko, "A service-oriented information system for collaborative research and doctoral education," in Int. Conf. E Bus. Eng., Shanghai, China, 2006, pp. 670-673.

[25] S. K. Rhee, J. Lee and M. W. Park, "RIKI: a wiki-based knowledge sharing system for collaborative research projects," 2008, http://www.springerlink.com/content/hv 7388u831x431p1/.

[26] Z. Itahriouan, A. Abtoy, K. E. El Kadiri, N. Aknin, "Validated CMS: Towards new generation of web content management systems on Web 2.0," I. J. Information Technology and Computer Science, vol. 12, 2012, pp. 4049, doi: 10.5815/ijitcs.2012.12.04.

[27] JISC (Joint Information Systems Committee), "Virtual research environments programme," 2004, http://www.jisc.ac.uk.

[28] NRC (National Research Council), National Collaboratories: Applying Information Technology for Scientific Research, National Academy Press, Washington, DC., 1993.
[29] S. Takao, "The effects of narrow-band width multipoint videoconferencing on group decision making and turn distribution," 1999 , http://portal.acm.org/citation.cfm?id=295665.295678.

[30] C. L. Borgman, "What can studies of e-learning teach us about collaboration in e-research? Some findings from digital library studies," Comp. Support Comp. W., vol. 15, 2006, pp. 359-383, doi:10.1007/s10606-006-9024-1.

[31] G. Konduri, and A. Chandrakasan, "A framework for collaborative and distributed Web-based design," 1999, http://ieeexplore.ieee.org/xpls/abs_all.jsp?arnumber=7822 $14 \& \operatorname{tag}=1$.

[32] B. Bunin, S. Ekins, and S. Louise-May, "Towards integrated web-based tools in drug discovery," Drug Discov. Today, vol. 6, 2010, pp. 17-21.

[33] I. Elsayed, G. Madey and P. Brezany, "Portals for collaborative research communities: two distinguished case studies," Concurr. Comp.-Pract. E., vol. 23, 2010, pp. 269-278, doi:10.1002/cpe.1685.

[34] P. Carmichael, "Extensible markup language and qualitative data analysis," 2002, http://www.qualitativeresearch.net/index.php/fqs/article/view/852.

[35] D. Gannon, B. Plale, M. Christie, Y. Huang, S. Jensen, N. Liu, S. Marru, S. L. Pallickara, S. Perera, S. Shirasuna, Y. Simmhan, A. Slominski, Y. Sun and N. Vijayakumar, "Building grid portals for e-science: A service-oriented architecture," Adv. Par. Com., vol. 16, 2008, pp. 149-166.

[36] Ultimus GmBH., "BPM for research excellence," 2006 , http://whitepapers.technologyevaluation.com/view_docu ment/6147/ultimus-case-study-bpm-for-researchexcellence.html.

[37] H. Bukvova, "Studying Research Collaboration: A Literature Review, Sprouts: Working Papers on Information Systems," 2010, http://sprouts.aisnet.org/10-3

[38] D. Stokols, S. Misra, R. Moser, K. Hall, B. Taylor, "The ecology of team science - understanding contextual influences on transdisciplinary collaboration," American Journal of Preventive Medicine, vol. 35, 2008, pp. 96-115, doi:10.1016/j.amepre.2008.05.003.

[39] B. Ju, S. Pawlowski, "Exploring the Barriers and Challenges of Information and Communication Technology Use in Distributed Research Today: A Ranking-type Delphi Study,” ASIST 2011, October 9-13, 2011, New Orleans, LA, USA.

[40] ISO, "ISO/IEC 9126-1: Information Technology Software Product Quality - Part1: Quality Model," 2001, http://www.iso.org/iso/catalogue_detail.htm?csnumber=2 2749.

Authors' Profiles

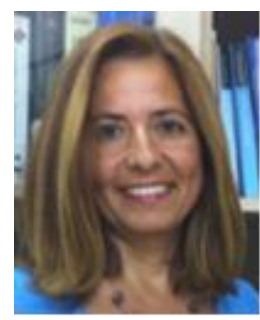

Asli Sencer, is full Professor at Department of Management Information Systems in Bogazici University, Istanbul, Turkey. She holds B.S., M.S. and Ph.D. degrees in industrial engineering. She gives graduate and undergraduate courses on operations management, quantitative decision making, supply chain management, information systems, and business process management. She publishes in high rank journals in her area of profession. Her recent papers are on the development of decision models and decision support systems for workforce management in call centers, supply chain management, and business process management. 


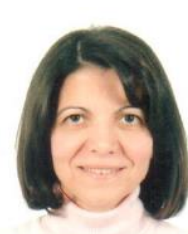

Meltem Ozturan, is full Professor at Department of Management Information Systems in Bogazici University, Istanbul, Turkey. She has completed her $\mathrm{PhD}$ in Quantitative Techniques in 1989. Dr Ozturan published as an author or as a coauthor scientific papers on her main research areas which are development and management of information systems, business process management, e-adoption, e-learning, artificial neural network applications, and project management.

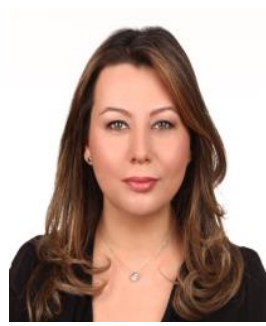

Hande Kimiloglu is Associate Professor at the Department of Management Information Systems in Bogazici University, Istanbul, Turkey. She has completed her $\mathrm{PhD}$ in Marketing in 2001 at Bogazici University. Her main research areas are online marketing, consumer behavior in the online environment, and various topics within the scope of e-business. Dr Kimiloglu published high quality scientific papers on her research areas.

How to cite this paper: Asli Sencer, Meltem Ozturan, Hande Kimiloglu,"A Web 2.0 Supported Business Process Management Environment for Collaborative Research", IJIEEB, vol.7, no.1, pp.8-17, 2015. DOI: 10.5815/ijieeb.2015.01.02 